\title{
Differential expression of the ICF (immunodeficiency, centromeric heterochromatin, facial anomalies) mutation in lymphocytes and fibroblasts
}

\author{
P MARASCHIO*, R TUPLER*, E DAINOTTI*, M PIANTANIDA*, \\ G CAZZOLA $\dagger$, AND L TIEPOLO* \\ From * Biologia Generale e Genetica Medica, Università di Pavia; and †Centro Fibrosi Cistica, Ospedale \\ Borgo Trento, Verona, Italy.
}

SUMmARY Fibroblasts from a patient with ICF syndrome were grown in the presence of excess of nucleotides, in media with different amounts of folic acid, and with caffeine in an attempt to $\mathrm{N}$ induce the chromosomal anomalies observed in lymphocytes. We induced despiralisation ando breakages in the centromeric heterochromatin of chromosomes 1 and 16 but not associations and multibranching. We suggest that the absence of the major chromosomal anomalies in fibroblasts $c$ from patients with ICF might be the result of both a longer $G_{2}$ in these cells and differential ${ }^{\gtrless}$ patterns of interphase heterochromatin associations in the two tissues.

The ICF syndrome is characterised by immunodeficiency, centromeric heterochromatin instability of chromosomes 1,9 , and 16 , and facial anomalies. ${ }^{1}$

In five of the six patients reported so far, obvious chromosomal anomalies were found only in lymphocytes, and in a case recently observed by Turleau et al (1989, personal communication) centromeric instability was not seen in fibroblasts either. Chromosome stretching, breakage, and arm duplications of chromosome 1 were seen in fibroblasts only in the case of Howard et al. ${ }^{2}$

In a previous paper ${ }^{1}$ we postulated that the chromosomal abnormalities in the ICF syndrome might be the result of a mutation interfering with the time of duplication of part of the centromeric heterochromatin and, as a consequence, of its condensation cycle.

Delayed chromatin condensation caused by late and incomplete replication is believed to control the expression of some fragile sites in human chromosomes. ${ }^{3}$

As in the ICF syndrome, fragile sites are not usually seen in cultured fibroblasts unless they are induced by experimental conditions.

We tried to induce in the fibroblasts of the patient described previously ${ }^{1}$ the chromosomal lesions typical of her lymphocytes, using agents or media known to interfere with DNA synthesis and to

Received for publication 7 February 1989 Accepted for publication 14 February 1989 increase fragile site expression: excess of nucleotides ${ }^{4}$ culture media deficient in folic acid, ${ }^{5}$ and caffeine. ${ }^{6}$

In addition we present some further clinical data $\stackrel{\Phi}{\varnothing}$ on the patient.

\section{Clinical data}

At the age of five and a half years the girl (fig 1 ) was readmitted to hospital for pulmonary infection andō on this occasion a new series of laboratory examina- $\frac{0}{3}$ tions was performed with the following results: $\operatorname{IgA}$ 10, IgG 295 , IgM $10 \mathrm{mg} \times 100 \mathrm{ml}$ (normal values for age, IgA $93 \pm 27$, IgG $929 \pm 228$, IgM $56 \pm 18$ ). These tests were performed before treatment with immuno-윽 globulins. Percentage reduction of B lymphocyte $>$ count was $\mathrm{SIg} 1 \%$ (normal $8 \pm 4 \%$ ) with totalo lymphocyte count $3220 / \mathrm{mm}^{3}$ (normal $>1500$ ). A N defect of chemotaxis of the polymorphonuclearneutrophil (PMNn) was investigated by means of a $N$ 'skin chamber'? 19510000 cells $/ \mathrm{cm}^{2} / 24$ h with N PMNn 90.3\% (normal $63635000 \pm 8252958$ PMNnO $>90 \%$ ). Cell mediated immunity, phagocytosis and $\mathrm{O}_{2}^{-}$production of PMNn was normal. HLA: A10, A28, B8, B27, Cw1, Cw2.

Since the last examination the girl has failed to 0 thrive and her height is now $102 \mathrm{~cm}$ (3rd to 10th centile) and weight $14.6 \mathrm{~kg}$ (<3rd centile). She $\stackrel{\mathbb{\triangle}}{\stackrel{1}{0}}$ has severe chronic bronchitis with bronchiectasis $\overrightarrow{\mathbb{D}}$ throughout the lower lobes and purulent broncho- $\frac{}{\sigma}$ rrhoea levels above $10 \mathrm{ml} / 24 \mathrm{~h}$; she has maxillary 


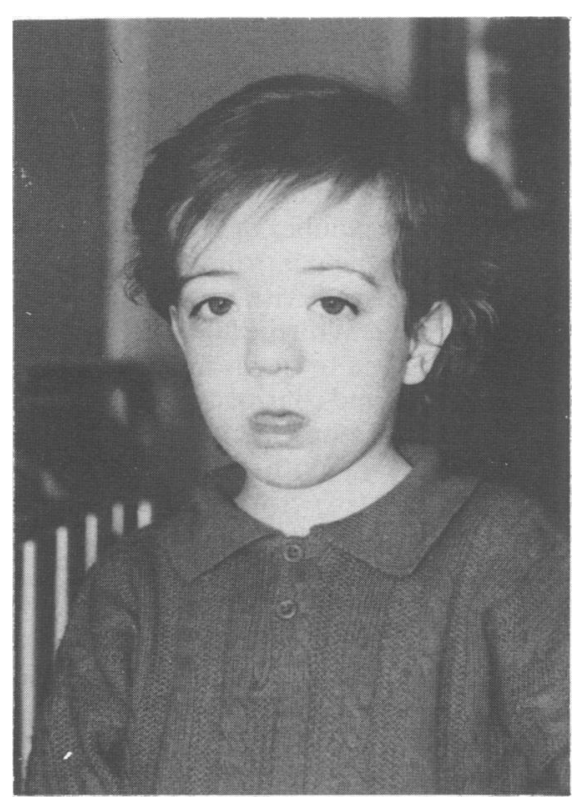

FIG 1 The patient at five and a half years.

sinusitis and conductive bradyacusia with tympanic damage from previous otitis.

\section{Materials and methods}

The effect of different concentrations of folic acid in the culture medium was studied by growing fibroblasts in Ham's F10 (1.3 mg/l folic acid) supplemented with $20 \%$ bovine serum, in TC 199 $(0.01 \mathrm{mg} / \mathrm{l}$ folic acid) supplemented with $5 \%$ bovine serum for 48 hours, and in MEM without folic acid (MEM-FA) with $5 \%$ bovine serum for 48 hours.

Excess of nucleotides was studied by growing fibroblasts in medium $\mathrm{F} 10$ in the presence of thymidine at concentrations of 600 and $300 \mu \mathrm{g} / \mathrm{ml}$, continuously for 24 hours (experiments 1 and 2 ), or for 17 hours followed by seven hours in TC 199 after removal of excess of thymidine (experiments 3 and 4). Similarly, adenosine $5^{\prime}$-triphosphate $(500 \mu \mathrm{g} / \mathrm{ml})$ was added for 24 hours (experiment 5) or for 17 hours +seven hours in TC 199 after removal of the excess adenosine (experiment 6).

The effect of caffeine was studied by adding $2.2 \mathrm{mmol} / \mathrm{l}$ of the substance for six hours to cells grown in F10 and in MEM-FA (experiments 7 and 8).

All cultures were exposed to colcemid $(0.02 \mu \mathrm{g} / \mathrm{ml})$ for the last three hours.

Chromosome preparations in all the experiments were stained with DA-DAPI.

The length of $G_{2}$ in fibroblasts was determined with a pulse of 20 minutes of tritiated thymidine (Amersham, specific activity $5 \mu \mathrm{Ci} / \mathrm{mmol} / \mathrm{l}$ ) at a concentration of $1 \mu \mathrm{Ci} / \mathrm{ml}$ and then processing the cultures after three, four, five, six, seven, and eight hours in medium without ${ }^{3} \mathrm{H}-\mathrm{TdR}$. Colcemid $(0 \cdot 02$ $\mu \mathrm{g} / \mathrm{ml})$ was added for the last 30 minutes. The proportions of labelled metaphases were scored after autoradiography with NTB2 Kodak emulsion.
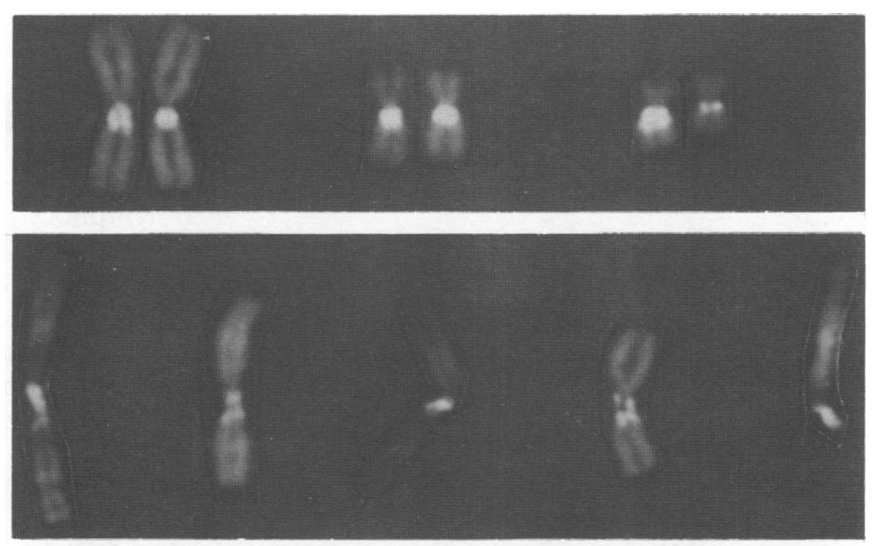

FIG 2 (a) Chromosomes 1, 9, and 16 with normal appearance of the centromeric regions from patient's fibroblast cultures.

Chromosomes 1 (b) and 16 (c) with various degrees of stretching up to breakage.

(DA-DAPI staining.)

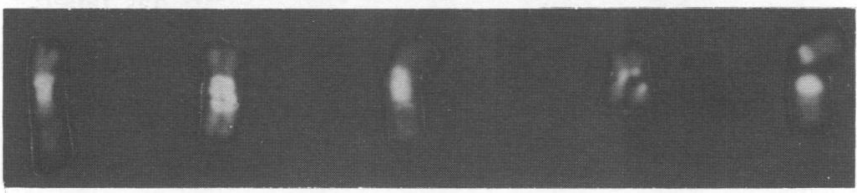




\section{Results}

The most striking chromosomal abnormalities found in ICF lymphocyte cultures (multibranched configurations and associations of chromosomes 1,9 , and 16) were not induced in fibroblasts by any of the experiments. However, we found various degrees of despiralisation of the centromeric heterochromatin of chromosomes 1 and 16 , which is the most frequent anomaly in lymphocytes.

In some metaphases these chromosomes appeared stretched up to breakage of one or both chromatids (fig 2). Chromosome 9 was less frequently stretched and was never broken.

To ascertain the possible presence of these minor anomalies, we re-examined the cultured fibroblasts obtained at the first examination of the patient, which in our previous paper ${ }^{1}$ were reported to have no abnormalities.

We found five cells with despiralisation of chromosomes 1 or 16 or both among the 91 cells analysed $(5 \cdot 5 \%)$, a frequency not significantly different from that found in control fibroblasts $(2 \cdot 0 \%)$.

Table 1 shows the results obtained in the patient and control fibroblasts grown in media with different amounts of folic acid: Ham's F10, TC 199, and? MEM-FA.

The frequency of anomalies in the patient's fibroblasts increased to $74 \%$ in cells grown in MEMFA and to $68 \%$ in TC 199 compared with $6.8 \%$ and $20.6 \%$, respectively, in control fibroblasts. The differ-元 ences between the number of cells with anomalies in $\mathrm{Q}$ the patient and in the control are highly significant.

The results obtained with an excess of thymidine $\vec{\circ}$ are shown in table 2 . With the highest dose $(600 \mu \mathrm{g} / \mathrm{ml},-$ experiment 1 ) only a few cells in mitosis were foundw in both the patient and control cultures and the differ-? ence between the number of cells with anomalies was not significant. With $600 \mu \mathrm{g} / \mathrm{ml}$ followed byin addition of TC 199 (experiments 3 and 4) and with a lower dose $(300 \mu \mathrm{g} / \mathrm{ml}$, experiment 2$)$, the differencesi between patient and control cells are significant. ON

In all the experiments chromosome 1 was theo most frequently involved in despiralisation, followed. by chromosomes 16 and 9 .

An excess of adenosine (table 2, experiment 5$)^{\frac{c}{<}}$ produced no significant difference in the induction $\overrightarrow{0}$ of anomalies between patient and control. Aftero culture in medium free of folic acid (experiment 6) the frequencies of anomalies in the two systemso

TABLE 1 Effects of different concentrations of folic acid in the culture medium on ICF fibroblasts.

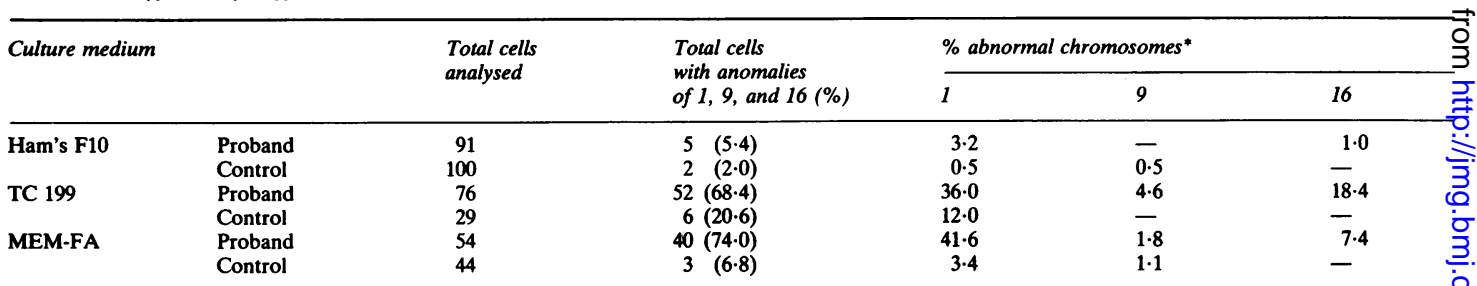

*In this and in the following tables the frequencies of abnormal chromosomes 1, 9, and 16 are calculated on the total number of these chromosomes in the cells analysed.

TABLE 2 Effects of an excess of thymidine and adenosine on ICF fibroblasts.

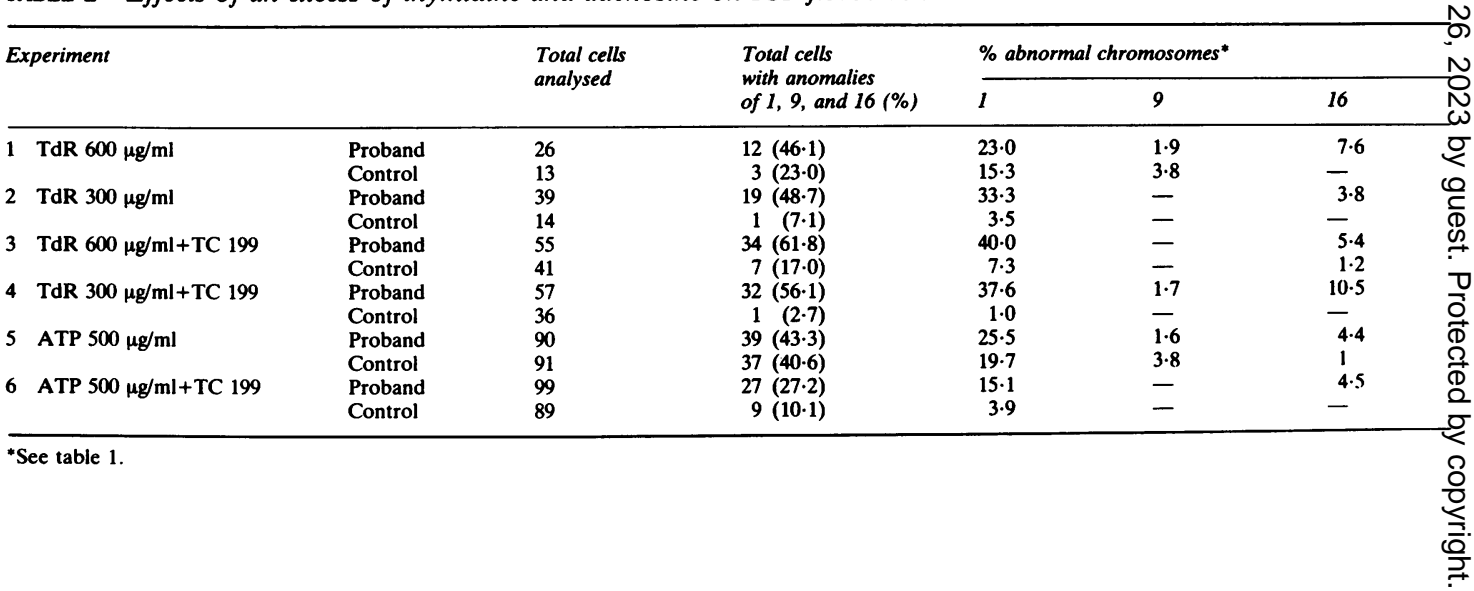


TABLE 3 Effects of caffeine on ICF fibroblasts.

\begin{tabular}{|c|c|c|c|c|c|c|c|}
\hline \multicolumn{3}{|c|}{ Experiment } & \multirow{2}{*}{$\begin{array}{l}\text { Total cells } \\
\text { analysed }\end{array}$} & \multirow{2}{*}{$\begin{array}{l}\text { Total cells } \\
\text { with anomalies } \\
\text { of } 1,9 \text {, and } 16(\%)\end{array}$} & \multicolumn{3}{|c|}{$\%$ abnormal chromosomes } \\
\hline & & & & & 1 & 9 & 16 \\
\hline \multirow{2}{*}{\multicolumn{2}{|c|}{7 Caffeine in Ham's F10 }} & Proband & 100 & $30(30 \cdot 0)$ & $18 \cdot 0$ & $1 \cdot 0$ & $7 \cdot 5$ \\
\hline & & Control & 101 & $8(7 \cdot 9)$ & 3.9 & - & - \\
\hline \multirow[t]{2}{*}{8} & Caffeine in MEM-FA & Proband & 48 & $39(81 \cdot 2)$ & $50 \cdot 0$ & $2 \cdot 0$ & $9 \cdot 0$ \\
\hline & & Control & 71 & $15(21 \cdot 1)$ & $7 \cdot 7$ & $2 \cdot 8$ & - \\
\hline
\end{tabular}

*See table 1.

were reduced, but were significantly higher in the patient's cells.

Caffeine added to F10 medium for the last six hours of culture (table 3 , experiment 7 ) resulted in a higher frequency of anomalies in the patient than in the control, although the overall frequency of the patient's cells with anomalies was lower than that in cultures treated with an excess of nucleotides.

If cells were grown for the same period of time in MEM-FA plus caffeine (experiment 8 ) the frequency of cells with anomalies was further increased both in the patient and in the control $(81 \%$ and $21 \%$, respectively).

The mean length of $G_{2}$ measured in fibroblasts from the patient and from a control did not differ significantly at five and a half hours and slightly more than five hours respectively.

\section{Discussion}

Excess of thymidine is known to result in a decrease of deoxycytidine (dCTP) and folic acid deficiency in a reduction of thymidine monophosphate (dTMP). ${ }^{8}$

Both these conditions, leading to alterations of the nucleotide pools, increased the frequency of chromosome anomalies in the ICF patient's fibroblasts when compared with those from a control.

These results could be interpreted as suggested by Laird $e t \mathrm{al}^{3}$ to explain the expression of fragile sites: the mutation present in the ICF syndrome could result in a delay in duplication of the late replicating pericentromeric regions of chromosomes 1,9 , and 16. In this situation any disturbance in the availability of nucleotides further shifts duplication of these regions towards $G_{2}$, leading to their incomplete condensation. The observed increase of chromosome anomalies in ICF fibroblasts treated with caffeine, which is supposed to shorten the $G_{2}$ period, ${ }^{9}$ seems to support this hypothesis.

Caffeine is known to induce a marked increase in the expression of fragile sites if used in combination with other inducers, such as FUdR ${ }^{6}$ or aphidicolin, ${ }^{10}$ or in cultures deprived of thymidine. ${ }^{11}$ In our experiments, adding caffeine to cells grown in a folic acid free medium, we obtained the maximum frequency $(81 \%)$ of ICF fibroblasts with anomalies.

A longer $G_{2}$ in fibroblasts than in lymphocytes is the probable reason for the observed lower expression of ICF chromosome abnormalities in the former tissue, in which decondensation must somehow be induced.

Because it was impossible to estimate directly the length of $G_{2}$ in ICF lymphocytes, we compared the duration of $G_{2}$ in the patient's fibroblasts ( 5.5 hours) and in normal fibroblasts $(5 \cdot 2$ hours) with the time of $2 \cdot 3$ to $3 \cdot 5$ hours reported for normal lymphocytes. ${ }^{12}$ The length of $G_{2}$ in fibroblasts, both normal and from the ICF patient, was longer than in normal lymphocytes.

The frequency of anomalies seen in chromosome 9 was similar to that found in controls, which could be the result of a different composition of its centromeric heterochromatin. Recently two repetitive DNA clones have been shown to be related to the centromeric heterochromatin of chromosomes 1,9 , and 16: clone pHuR195, isolated from satellite DNA II, is specific for chromosome 16 but, at low stringency conditions, hybridises also with chromosome 1 , while satellite III related clone pHuR98 hybridises with chromosome 9 only. ${ }^{13}$ This indicates a similarity in the centromeric heterochromatin of chromosomes 1 and 16, while that of chromosome 9 shows a different composition.

Heterogeneity of the centromeric heterochromatin of the three chromosomes was already indicated by the different behaviour of chromosomes 1 and 16 in comparison with 9 when stained with DAPI/actinomycin $D^{14}$ or $\mathrm{G} 11.1^{15}$

We can therefore assume that the mutation in ICF mainly affects specific sequences of chromosomes 1 and 16. The absence in ICF fibroblasts of the most striking chromosome anomalies (multibranching and association with fusion of centromeric heterochromatin) and the failure to induce these abnormalities could be because the interphase association patterns of centromeric heterochromatin of chromosomes 1,9 , and 16 are different in lymphocytes and fibroblasts. These chromosomes are known to asso- 
ciate in lymphocyte interphase,$^{16}$ while no data are available, to our knowledge, for fibroblasts. Preliminary observations on the association of positive DA-DAPI bodies in interphase nuclei in the two tissues indicate a high number of cells without chromocentres in fibroblasts, while in lymphocytes the DA-DAPI positive bodies varied between two and eight with the majority of cells showing four bodies (data not shown).

Variations in the pattern of heterochromatin association in different tissues has been reported ${ }^{17}$ in the mouse.

In conclusion, we think that the mutation responsible for the ICF syndrome affects primarily the duplication time of at least part of the centromeric heterochromatin of chromosomes 1 and 16.

The variation of expression at the chromosomal level of this defect, that is, decondensation, in different tissues depends on the length of $G_{2}$. In fact, the frequency of anomalies in fibroblasts was increased by shifting DNA duplications towards $G_{2}$. In turn, different patterns of interphase heterochromatin association in lymphocytes and fibroblasts can lead to the formation of the more complex anomalies in the former tissue.

This work was supported in part by Associazione per lo Studio delle Malformazione, Milano. We thank Professor M Fraccaro for critical reading of the manuscript.

\footnotetext{
References

' Maraschio P, Zuffardi O, Dalla Fior T, Tiepolo L. Immunodeficiency, centromeric heterochromatin instability of chromosomes 1,9, and 16, and facial anomalies: the ICF syndrome. J Med Genet 1988;25:173-80.

2 Howard PJ, Lewis IJ, Harris F, Walker S. Centromeric instability of chromosomes 1 and 16 with variable immune deficiency: a new syndrome. Clin Genet 1985;27:501-5.
}

${ }^{3}$ Laird C, Jaffe E, Karpen G, Lamb M, Nelson R. Fragile sites in human chromosomes as regions of late replicating DNA. Trends Genet 1987;3:274-81.

${ }^{4}$ Sutherland GR, Baker E. Effects of nucleotides on expression of the folate sensitive fragile sites. Am J Med Genet 1986;23: 409-17.

5 Sutherland GR. Heritable fragile sites on human chromosomes. I. Factors affecting expression in lymphocyte cultures. Am J Hum Genet 1979;31:125-35.

6 Abruzzo MA, Pettay D, Mayer M, Jacobs PA. The effect of caffeine on fragile X expression. Hum Genet 1986;73:20-2.

7 Senn H, Holland JF, Banerjee T. Kinetic and comparative studies on localized leucocyte migration in normal man. $J$ Lab Clin Med 1969;74:742-56.

${ }^{8}$ Kunz BA. Genetic effects of deoxyribonucleotide pool imbalances. Environ Mutagen 1982;4:695-725.

9 Hansson K, Natarjan AT, Kihlman BA. Effect of caffeine in $\mathbf{G}_{2}$ on X-ray induced chromosomal aberrations and mitotic inhibition in ataxia telangectasia fibroblast and lymphoblastoid cells. Hum Genet 1984;67:329-35.

10 Glover T, Coyle-Morris J, Morgan R. Fragile sites: overview, of occurrence in acute nonlymphocytic leukemia and effect of caffeine on expression. Cancer Genet Cytogenet 1986;19:141-50.

11 Yunis JJ, Soreng AL. Constitutive fragile sites and cancer. Science 1984;226:1199-204.

12 Giannelli F. Autoradiography of human chromosomes. In: Yunis JJ, ed. Human chromosome methodology. 2nd ed. New York, London: Academic Press, 1974:127-50.

13 Schwarzacher-Robinson T, Cram LS, Meyne J, Moyzis RK. Characterization of human heterochromatin by in situ hybridization with satellite DNA clones. Cytogenet Cell Genet 1988;47: 192-6.

14 Schweizer D. Distamycin-DAPI bands: properties and occurrence in species. In: Branaham PB, Bennett MD, eds. Kew Chromosome Conference II. London: Allen and Unwin, 1983 43-51.

15 Bobrow M, Madan K, Pearson PL. Staining of some specific regions of human chromosomes, particularly the secondary constriction of No 9. Nature 1972;238:122-4.

${ }^{16}$ Schmid M, Vogel W, Krone W. Attraction between centric heterochromatin of human chromosomes. Cytogenet Cell Genet 1975;15:66-80.

17 Hsu TC, Cooper JEK, Mace ML Jr, Brinkley BR. Arrangement of centromeres in mouse cells. Chromosoma 1971;34:73-87.

Correspondence to Dr L Tiepolo, CP 217, I-27100 Pavia, Italy. 